\title{
Bioactivation of pentaerythrityl tetranitrate by mitochondrial aldehyde dehydrogenase
} Martina Griesberger*1, Gerald Wölkart ${ }^{1}$, Antonius Gorren ${ }^{1}$, Matteo Beretta ${ }^{1}$, Verena Wenzl ${ }^{1}$, Juliane Brettschneider ${ }^{2}$, Andreas Seeling2, Jochen Lehmann², Michael Russwurm ${ }^{3}$, Doris Koesling ${ }^{3}$, Kurt Schmidt ${ }^{1}$ and Bernd Mayer ${ }^{1}$

\author{
Email: Martina Griesberger* - martina.griesberger@uni-graz.at \\ * Corresponding author \\ from 4th International Conference of cGMP Generators, Effectors and Therapeutic Implications \\ Regensburg, Germany. 19-21 June 2009 \\ Published: II August 2009 \\ BMC Pharmacology 2009, 9(Suppl I):PI7 doi:I0.II86/I47I-22I0-9-SI-PI7
}

Address: ${ }^{1}$ Department of Pharmacology and Toxicology, Karl-Franzens University, Graz, Austria, ${ }^{2}$ Institute of Pharmacy, Friedrich-SchillerUniversity, Jena, Germany and ${ }^{3}$ Department of Pharmacology and Toxicology, Ruhr-University, Bochum, Germany

This abstract is available from: http://www.biomedcentral.com/I47I-22I0/9/SI/PI7

(c) 2009 Griesberger et al; licensee BioMed Central Ltd.

\section{Background}

Organic nitrates represent a class of very effective antiischemic drugs used for the treatment of angina pectoris, myocardial infarction and congestive heart failure [1]. A limitation of their clinical use is the development of nitrate tolerance. A remarkable exception is the long-acting drug pentaerythrityl tetranitrate (PETN), which was shown to cause no tolerance [2]. The mitochondrial isoform of aldehyde dehydrogenase (ALDH2) was shown to be involved in bioactivation of nitroglycerin (GTN) [3] and PETN [4]. The present work was carried out to study the molecular mechanisms underlying the pharmacological differences between GTN and PETN at the level of purified ALDH2.

\section{Results}

As quantified by liquid chromatography-mass spectroscopy (LC-MS) ALDH2 metabolized $50 \mu \mathrm{M}$ PETN to 14.84 $\pm 4.05 \mathrm{nmol} / \mathrm{min} / \mathrm{mg}$ pentaerythrityl trinitrate (PETriN) in the absence and $62.38 \pm 7.21 \mathrm{nmol} / \mathrm{min} / \mathrm{mg}$ PETriN in the presence of the reducing agent dithiothreitol. Co-incubation of $2 \mu \mathrm{M}\left[{ }^{14} \mathrm{C}\right] \mathrm{GTN}$ with ALDH2 and increasing concentrations of PETN resulted in only small decreases in 1,2-glyceroldinitrate formation as measured by radio thin layer chromatography (control: $7.98 \pm 0.20,1 \mu \mathrm{M}$ PETN: $7.95 \pm 0.20,10 \mu \mathrm{M}$ PETN: $7.41 \pm 0.18,100 \mu \mathrm{M}$ PETN: $6.66 \pm 0.50 \mathrm{nmol} / \mathrm{min} / \mathrm{mg}$ ) indicating that PETN does not compete with GTN metabolism. In the presence of $25 \mu \mathrm{g}$ of ALDH2 PETN activated soluble guanylate cyclase (sGC) with an $\mathrm{EC}_{50}$ of $3.61 \pm 0.35 \mu \mathrm{M}$ and a maximum at $30 \mu \mathrm{M}$ PETN $(2.67 \pm 0.12 \mu \mathrm{mol} / \mathrm{min} / \mathrm{mg})$. This effect was enhanced by superoxide dismutase (SOD) resulting in an $\mathrm{EC}_{50}$ of $0.64 \pm 0.08 \mu \mathrm{M}$ and maximal sGC activation $(18.44 \pm 0.27 \mu \mathrm{mol} / \mathrm{min} / \mathrm{mg}$ in the presence of $30 \mu \mathrm{M}$ PETN). ALDH2 activity, measured as formation of $\mathrm{NADH}$ from $\mathrm{NAD}^{+}$in the presence of acetaldehyde, was rapidly inactivated by GTN but not by PETN (1 mM each).

\section{Conclusion}

Low and high affinity pathways of PETN may explain the apparent differences between PETN metabolism and bioactivation, respectively. The reaction of PETN with ALDH2 leads to activation of sGC with markedly higher values in the presence of SOD suggesting formation of superoxide as a co-product of PETN metabolism. The lack of vascular tolerance to PETN may be due to significantly lower rates of ALDH2 inactivation as compared to GTN.

\section{Acknowledgements}

This work was supported by the Fonds zur Förderung der Wissenschaftlichen Forschung in Austria. 


\section{References}

I. Daiber A, Oelze M, Wenzel P, Wickramanayake JM, Schuhmacher S, Jansen T, Lackner KJ, Torzewski M, Münzel T: Nitrate tolerance as a model of vascular dysfunction: Roles for mitochondrial aldehyde dehydrogenase and mitochondrial oxidative stress. Pharmacol Rep 2009, 6 I:33-48.

2. Jurt U, Gori T, Ravandi A, Babaei S, Zeman P, Parker JD: Differential effects of pentaerythritol tetranitrate and nitroglycerin on the development of tolerance and evidence of lipid peroxidation: a human in vivo study. J Am Coll Cardiol 200I, 38:854-859.

3. Chen Z, Zhang J, Stamler JS: Identification of the enzymatic mechanism of nitroglycerin bioactivation. Proc Natl Acad Sci USA 2002, 99:8306-83II.

4. Daiber A, Oelze M, Coldewey M, Bachschmid M, Wenzel P, Sydow K Wendt M, Kleschyov AL, Stalleicken D, Ullrich V, Mülsch A, Münzel $\mathrm{T}$ : Oxidative stress and mitochondrial aldehyde dehydrogenase activity: a comparison of pentaerythritol tetranitrate with other organic nitrates. Mol Pharmacol 2004, 66: I372-I 382.

Publish with Bio Med Central and every scientist can read your work free of charge

"BioMed Central will be the most significant development for disseminating the results of biomedical research in our lifetime. "

Sir Paul Nurse, Cancer Research UK

Your research papers will be:

- available free of charge to the entire biomedical community

- peer reviewed and published immediately upon acceptance

- cited in PubMed and archived on PubMed Central

- yours - you keep the copyright

Submit your manuscript here:

http://www.biomedcentral.com/info/publishing_adv.asp 